\title{
The role of meteorological factors on year-to-year variability of nitrogen and sulphur deposition in the UK
}

\author{
M. Matejko ${ }^{1}$, A. Dore ${ }^{2}$, C. Dore ${ }^{3}$, M. Błaś ${ }^{1}$, M. Kryza $^{1}$, \\ R. Smith ${ }^{2} \&$ D. Fowler ${ }^{2}$ \\ ${ }^{1}$ Department of Meteorology and Climatology, \\ University of Wroctaw, Poland \\ ${ }^{2}$ Centre for Ecology and Hydrology, UK \\ ${ }^{3}$ AETHER Ltd., UK
}

\begin{abstract}
FRAME is a statistical Lagrangian model, which describes the main atmospheric processes (emission, diffusion, chemistry and deposition) taking place in a column of air. The model is used to calculate maps of dry and wet deposition for sulphur and nitrogen. Historical emissions data are used in the model to calculate changes in deposition of sulphur and oxidised and reduced nitrogen for the UK at a $5 \mathrm{~km} \times 5 \mathrm{~km}$ resolution for the years 1990-2005. Emissions of $\mathrm{SO}_{2}, \mathrm{NO}_{\mathrm{x}}$ and $\mathrm{NH}_{3}$ in the UK have fallen by $77 \%, 47 \%$ and $18 \%$ during this period. FRAME calculated reductions in wet deposition to the UK of $56 \%, 17 \%$ and $16 \%$ for $\mathrm{SO}_{\mathrm{x}}$, $\mathrm{NO}_{\mathrm{y}}$ and $\mathrm{NH}_{\mathrm{x}}$ respectively. Inter-annual variation in meteorology was found to have a significant influence on pollutant transport and the national wet and dry deposition budget. This occurred due to differing wind direction frequency as well as annual precipitation. When using year with specific wind conditions, wet deposition can even change by more than $20 \%$. It was also observed that wind conditions have a greater influence on deposition budget than precipitation data. Modelled trends in nitrogen and sulphur wet deposition have been compared with measurements from the national acid deposition monitoring network during this period. A more comprehensive monitoring network has been used to verify model results for deposition of $\mathrm{SO}_{4}{ }^{2-}, \mathrm{NO}^{3-}$, and $\mathrm{NH}^{4+}$ for the year 2005.
\end{abstract}

Keywords: emissions reduction, atmospheric circulation, long-range transport, pollutant deposition, UK. 


\section{Introduction}

Deposition rate does not necessarily decrease with the distance from emission sites and meteorological factors are crucial for controlling the spatial and temporal distribution of both concentration and deposition of pollutants. Atmospheric resistance times of $\mathrm{SO}_{2}$ and $\mathrm{NO}_{\mathrm{x}}$ are even several days and pollutants can be transported about a thousand of kilometers [20]. In many countries deposition to a large extend comes from outside sources and it is necessary to assess the changes on a large scale, considering the trans-boundary fluxes [10]. The effective pollutants removal is caused by chemical liquid-phase transformations in clouds $[12,21]$ and water flux from the atmosphere to the ground especially in the form of precipitation. It could affects soils and freshwater, particularly in areas where annual precipitation is high [19].

Analysis of meteorological conditions showed that inter-annual variation of circulation patterns and precipitation play a significant role in causing year-toyear fluctuations. Hence it is an important component in long range transport modelling, pollutant deposition researches and policy analysis $[3,11]$. In the UK Lagrangian trajectory models such as HARM [18], TRACK [17] and FRAME (the Fine Resolution Atmospheric Multi-pollutants Exchange model) [22] have been developed to assess acid deposition to sensitive areas. Air pollution predictions are usually constructed by keeping the climate constant and only changing the emission [15]. A first pilot study of the impact of regional climate change on deposition of sulphur and nitrogen in Europe was presented by Langer and Bergstrom [14]. Variability of meteorological factors from year to year is important to understand non-linearity in the emission-deposition relationship. They also complicate the process of assessing the effects of emission reduction strategies [10].

In this paper, we use FRAME model to consider the important contribution of meteorological data to deposition budget of $\mathrm{SO}_{\mathrm{x}}, \mathrm{NO}_{\mathrm{y}}$ and $\mathrm{NH}_{\mathrm{x}}$ in the UK. The accuracy of the model is verified by a detailed comparison with measurements from the UK national monitoring networks for ion concentration in precipitation for the year 2005 and also UK budget comparison for the period 1990-2005.

\section{FRAME model}

\subsection{Model description}

The atmospheric transport model, FRAME (Fine Resolution Atmospheric Multipollutant Exchange) is used to assess the long-term annual mean sulphur and nitrogen deposition over UK. Detailed description of the FRAME model is provided by Singles et al. [22], Fournier et al. [9] and Dore et al. [7]. FRAME is a Lagrangian model which describes the main atmospheric processes taking place in a column of air moving along straight-line trajectories following specified wind directions. The model consists of 33 vertical layers of varying thickness ranging from $1 \mathrm{~m}$ at the surface and increasing to $100 \mathrm{~m}$ at the top of the domain [1]. Vertical mixing is described using K-theory eddy diffusivity, and 
solved with a Finite Volume Method [24]. Dry deposition is calculated by determining a vegetation velocity $\left(\mathrm{V}_{\mathrm{d}}\right)$ to each chemical species derived from a dry deposition model [23]. This model derives maps of deposition velocity taking into account surface properties and geographical and altitudinal variation of windspeed. Wet deposition is calculated with scavenging coefficient and a constant drizzle approach, using precipitation rates calculated from a map of average annual precipitation. The amount of material removed in a time period $(\Delta t)$ is given by

$$
\Delta \mathrm{c}_{\mathrm{i}}=\mathrm{c}_{\mathrm{i}}\left(1-\mathrm{e}^{-\lambda \mathrm{i} \Delta t}\right)
$$

$\Delta c_{i}-$ decrease in concentration of species i due to removal by precipitation, $\lambda_{\mathrm{i}}-$ scavenging coefficient.

The wet deposition flux to the surface is the sum of wet removal from all volume elements aloft, assuming that scavenged material comes down as precipitation. There is no difference between in-cloud and below-cloud processes and an averaged value of scavenging ratio $\left(\Delta_{\mathrm{i}}\right)$ is used in the model. To produce scavenging coefficient $\lambda_{\mathrm{i}}, \Delta_{\mathrm{i}}$ is combined with the precipitation rate and the depth of the mixing layer $\Delta \mathrm{H}_{\text {mix }}$ :

$$
\lambda_{\mathrm{i}}=\left(\Delta_{\mathrm{i}} \mathrm{P}\right) / \mathrm{H}_{\text {mix }}
$$

An increased washout rate is assumed over hill areas due to the seeder-feeder effect. It is assumed that the washout rate for the orographic component of rainfall is twice that used for the non-orographic components [5]. As air columns move along its trajectory, chemical interactions between $\mathrm{NH}_{\mathrm{x}}, \mathrm{SO}_{\mathrm{x}}$ and $\mathrm{NO}_{\mathrm{y}}$ take place. The parameterisation combine descriptions of both dry chemistry and aqueous phase chemistry.

The FRAME domain covers the UK and the Republic of Ireland with a grid resolution of $5 \mathrm{~km} \times 5 \mathrm{~km}$ and grid dimension of $172 \times 244$. Input pollutant concentrations at the boundary of the model domain are calculated with FRAME-Europe - a similar model which runs on the EMEP grid at $50 \mathrm{~km} \times 50$ $\mathrm{km}$ resolution. Trajectories are advected with different starting angles at a 1degree resolution, using directionally dependent wind speed and wind frequency roses. To create wind speed rose for FRAME radiosonde data are used [6], but wind frequency rose is based on the Jenkinson objective classification).

\subsection{Emissions input data}

The FRAME model uses a database of $\mathrm{SO}_{2}, \mathrm{NO}_{\mathrm{x}}, \mathrm{NH}_{3}$ emissions with a $5 \mathrm{~km} \mathrm{x}$ $5 \mathrm{~km}$ grid-square resolution as input. Emissions of $\mathrm{SO}_{2}$ and $\mathrm{NO}_{\mathrm{x}}$ are taken directly from the National Atmospheric Emissions Inventory (NAEI, www.naei.org.uk) for the UK. Emissions of ammonia are estimated for each grid square using the AENEID model (Atmospheric Emissions for National Environmental Impacts Determination) that combines data on farm animal numbers, with land cover information, as well as fertiliser application, crops and non-agricultural emissions [8]. In order to estimate the temporal trends in deposition to the UK, it is important for input emissions data to be identically 
formatted. The background and point sources emissions for the year 2002 were taken to be the baseline year. The data for point sources and area emissions were used to scale emissions backwards and forwards in time and generate new emissions file for the years 1990-2001. Emissions from NAEI were used for 2003, 2004, and 2005. Emissions from the Republic of Ireland were scaled backwards in time in a similar manner to the UK emissions. $\mathrm{SO}_{2}$ and $\mathrm{NO}_{\mathrm{x}}$ emissions from international shipping were also included in the domain and were scaled forwards and backwards in time from the baseline year 2000 according to estimates from the NAEI.

For the period 1990-2005, $\mathrm{SO}_{2}$ emissions are dominated by coal combustions, primarily in Public Electricity and Heat Generation. The emissions have been reduced from $1859 \mathrm{Gg} \mathrm{S}$ in 1990 to $344 \mathrm{Gg} \mathrm{S}$ in 2005 and the significant reductions have been caused by fuel switching from coal to gas, and the installation of the abatement equipment at power stations. At the same period the reduction in emissions for $\mathrm{NO}_{\mathrm{x}}$ amounts from $903 \mathrm{Gg} \mathrm{N}$ to $493 \mathrm{Gg} \mathrm{N}$, where the largest reduction has been from Passenger Cars. This is due to the introduction of three-way-catalysts in the late 1990's. Emissions from power generation have also reduced, primarily due to the increased use of gas over coal-fired stations. Emissions of $\mathrm{NH}_{3}$ are dominated by agricultural activities. The reduction in emissions observed for $\mathrm{NH}_{3}$ is not as large as that for $\mathrm{SO}_{2}$ and $\mathrm{NO}_{\mathrm{x}}$. The total $\mathrm{NH}_{3}$ emission has changed from $315 \mathrm{Gg} \mathrm{N}$ in 1990 to $259 \mathrm{Gg} \mathrm{N}$ in 2005. This has primarily been caused by a decrease in livestock numbers or improvements to manure management.

\subsection{Meteorological data}

Precipitation data used in FRAME comes from the Meteorological Office national network (approximately 5000 stations). The data are in the form of annual rainfall fields for the UK and Ireland, with the resolution $5 \mathrm{~km} \times 5 \mathrm{~km}$. For the period 1990-2005 the mean annual precipitation was $1130 \mathrm{~mm} \mathrm{yr}^{-1}$. The wettest years were: 1998, 2000 and 2002 (> $1260 \mathrm{~mm}$ ), while 1996 and 2003 were dry $(<920 \mathrm{~mm})$, relative to the mean for the period (fig. 1). A higher precipitation amount is noticed at the western costal and at higher altitudes, however during the wet year, hilly regions with precipitation above $2000 \mathrm{~mm}$ year $^{-1}$ are considerably larger. The considerable enhancement in rainfall in hilly regions can be partially explained with seeder-feeder mechanism [2, 4].

Wind data (frequency and wind speed information) was taken from the objective classification and radiosonde. Wind direction frequency roses are based on objective classification of Lamb-Jenkinson weather types $[13,16]$. For each year there is different wind frequency rose. The average (1990-2005) wind rose illustrates that predominant wind directions are from the SW-W (fig. 2(a)). The years 1996 and 2004 were selected to show the difference in wind frequency from $\mathrm{E}+\mathrm{SE}+\mathrm{S}$ directions (most polluted) within the considered period (fig. 2). The wind speed rose was generated by calculating the harmonic mean from the mean radiosonde data set (fig. 2(b)), The highest wind speeds are observed from the southwest and lower from the east. 


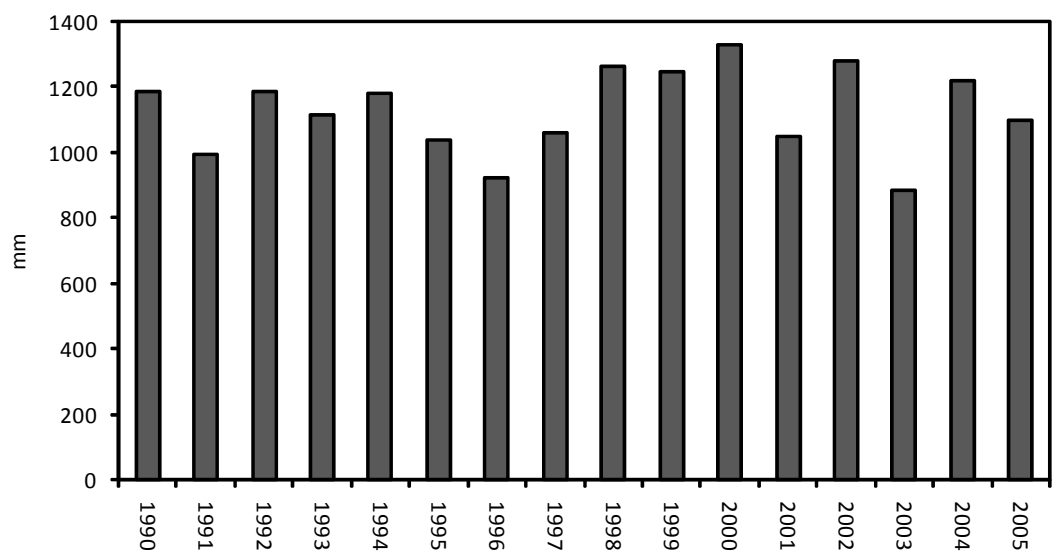

Figure 1: $\quad$ Mean annual UK precipitation 1990-2005.
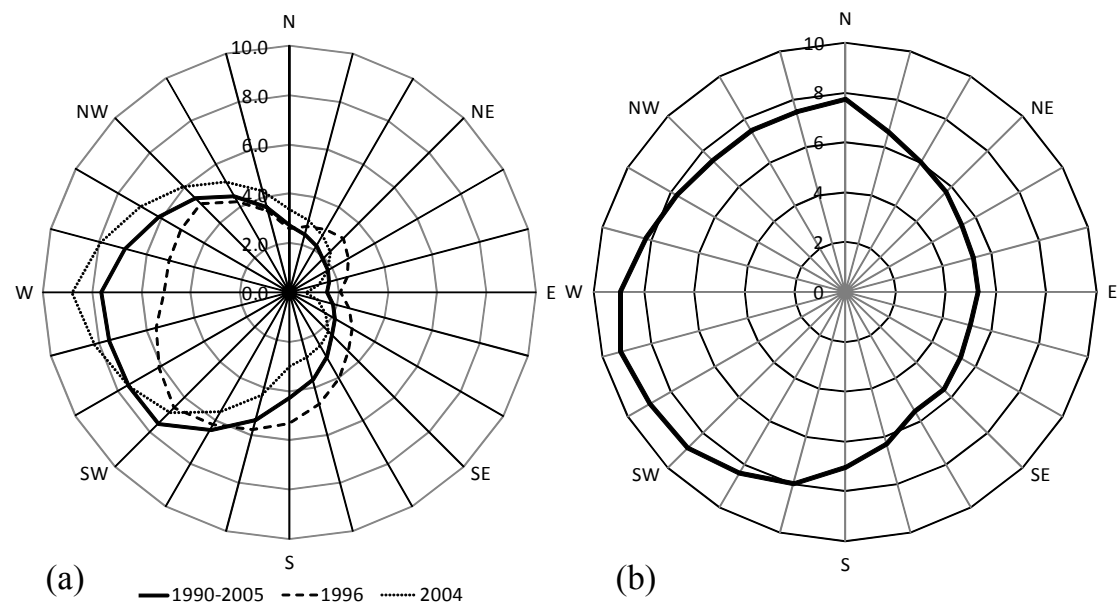

Figure 2: $\quad$ The 1990-2005 average wind frequency rose compare to 1996 and 2004 wind frequency roses (figure (a)), [\%]). 1990-2005 harmonic average radiosonde wind speed rose (figure (b)), $\left[\mathrm{m} \mathrm{s}^{-1}\right]$ ).

\section{Results and discussion}

\subsection{Comparison of model outputs with measurements}

Assessment of the accuracy of FRAME in estimating deposition has been made by comparison modelled data against measurements. Wet deposition data were obtained from the secondary acid precipitation monitoring network (32 sites). Unfortunately, long-term dry deposition is only measured directly at a very few 
sites in the UK, which means a direct model-measurement comparison dry deposition is not feasible.

The measurements data $\left(\mathrm{NH}_{4}^{+}, \mathrm{NO}_{3}{ }^{-}, \mathrm{SO}_{4}{ }^{2-}\right)$ were compared with modelled for the year 2005 (fig. 3). A good statistics measures (MB, MAE, R) are evident for all compounds. A satisfactory correlation for wet deposition of sulphate is apparent, with a slope of 1.10 and low intercept of 0.17 for the modelmeasurement linear regression.

The model performs particularly well against measurements for low deposition and somewhat overestimates higher values (which usually occurs in hilly regions). For $\mathrm{NO}_{3}{ }^{-}$and $\mathrm{NH}_{4}{ }^{+}$lower deposition is also represented better but higher values appears both as overestimations and underestimations.

Modelled results were also compared with the country deposition budget (fig. 4). Solid lines, which are quite flat for all compounds show FRAME
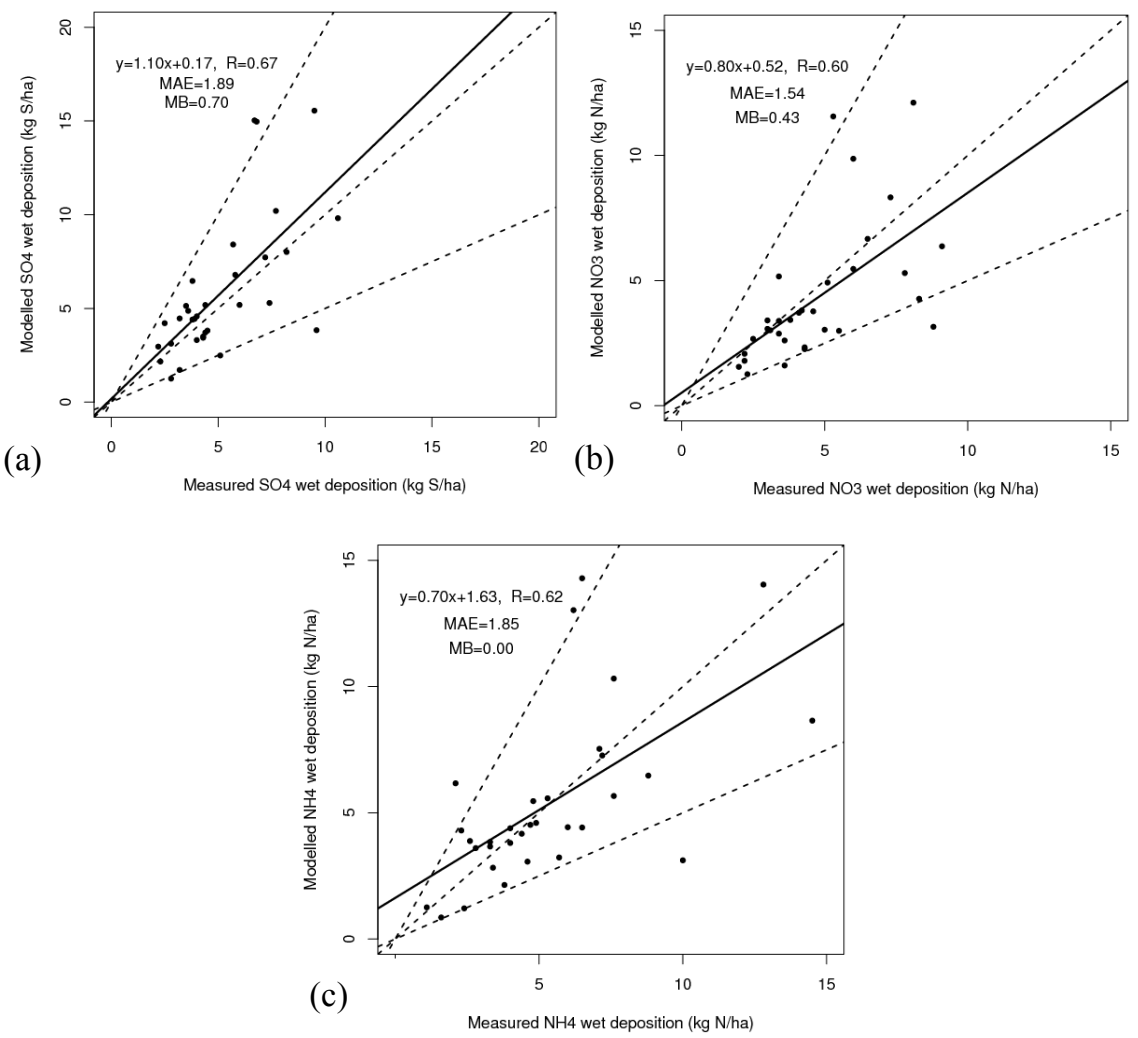

Figure 3: Correlation of modelled wet deposition with measurements from the national monitoring network for 2005: (a) $\mathrm{SO}_{4}{ }^{2-}$, (b) $\mathrm{NO}_{3}{ }^{-}$, (c) $\mathrm{NH}_{4}^{+}$. Solid line is the best fit line produced by a regression analysis, dashed lines are for reference: $2: 1,1: 2$ and 1:1 division. 


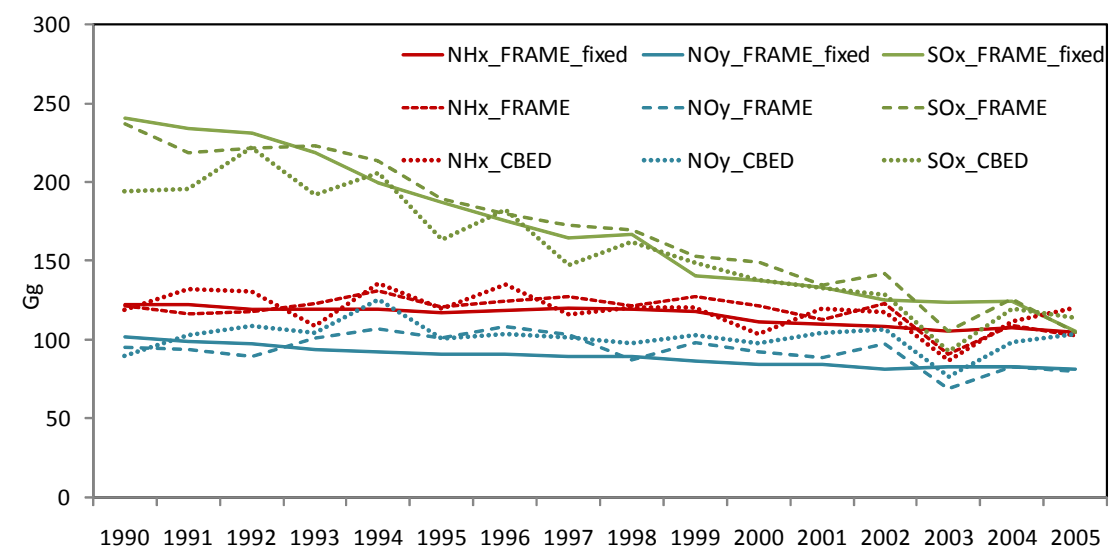

Figure 4: Comparison the country wet deposition budget estimated by FRAME (using specific meteorological conditions or without considering the meteorological influence - "fixed") and CBED (Concentration Based Estimated Deposition).

deposition budget counted without considering the meteorological influence. The FRAME wet deposition budgets for the UK show reductions of $132 \mathrm{Gg}$ S$\mathrm{SO}_{\mathrm{x}} \mathrm{yr}^{-1}, 15 \mathrm{Gg} \mathrm{N}^{-N} \mathrm{yr}^{-1}$ and $19 \mathrm{Gg} \mathrm{N}^{-N_{H}} \mathrm{yr}^{-1}$ over the period 1990-2005. There is a very good agreement between modelled and measured lines. FRAME model seems to catch quite well specific meteorological conditions (special peaks in 2002 or 2003).

\subsection{Influence of meteorological data on regional budget}

To check the influence of meteorological data on deposition budget, FRAME is run using emissions data from the year 2005 , and specific wind frequency roses (fig. 2) and annual precipitation (fig. 1) from the period 1990-2005 are selected. First two simulations contain an average (1990-2005) wind frequency rose and precipitation data for the driest (2003) and wettest (2000) year of the analyzed period. For the driest year the annual sum of precipitation is about $22 \%$ lower than average and for wettest year by about $18 \%$ higher than average. The next two simulations are run using an average (1990-2005) precipitation data and specific wind roses: 1996 and 2004. For 1996 wind rose, there are more easterly directions (NNE-SSW) and for 2004 more westerly and northerly directions (WSW-NE) than average. There is also run simulation with average conditions wind frequency rose and annual precipitation data averaged for the period.

Fig. 5 shows relative changes in wet and dry deposition results between simulations with specific and average meteorological conditions. Comparing simulations results for wet and dry year, it is characteristic that all species show similar reaction. Simultaneously, meteorological conditions have a greater influence on wet deposition than dry. In 2003 year, with $22 \%$ lower annual sum of precipitation corresponds to $13 \%$ lower wet deposition. It is clearly seen that 
greater influence on deposition budget between species have changes of wind conditions than precipitation. When using wind rose from the most polluted directions (1996) wet deposition is higher by about $22 \%, 14 \%$ and $12 \%$ for $\mathrm{NO}_{\mathrm{y}}$, $\mathrm{SO}_{\mathrm{x}}$ and $\mathrm{NH}_{\mathrm{x}}$, respectively.

The ratio of spatial distribution of wet deposition between simulation with specific wind roses and average simulation are presented in fig. 6 . Wet deposition of $\mathrm{SO}_{\mathrm{x}}, \mathrm{NO}_{\mathrm{y}}$ and $\mathrm{NH}_{\mathrm{x}}$ is locally higher than average by about $40 \%$ when using wind rose for 1996 (higher contribution of E, SE and S wind sectors). It concerns especially hilly regions on the west and north parts in UK. For the rest areas wet deposition is higher by about $10-15 \%$. There is lower deposition in some areas along the east coast, where major power stations are situated. Using 2004 wind rose (extremely westerly oriented), north parts of UK are seen to have lower deposition by about $10-15 \%$ but there are also areas with raised deposition to the south of emission sources in major urban areas of Greater London, Birmingham and Manchester.

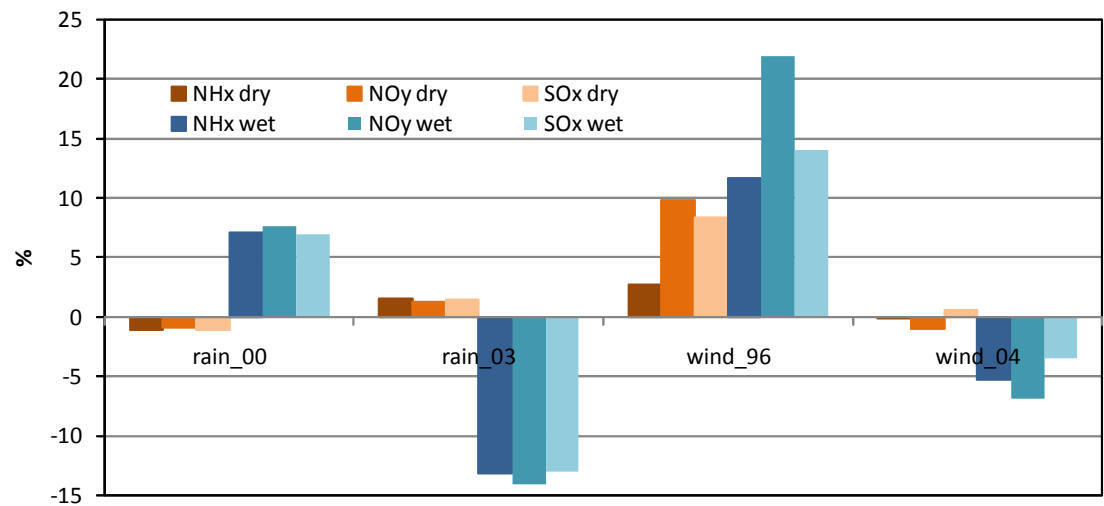

Figure 5: Relative changes in dry and wet deposition of $\mathrm{SO}_{\mathrm{x}}, \mathrm{NO}_{\mathrm{y}}, \mathrm{NH}_{\mathrm{x}}$ between simulations with specific and average meteorological conditions (rain_00 - wettest and rain_03 - driest year; wind_96 more E directions and wind_04-more W and NW directions than an average).

\section{Conclusions}

Inter-annual variability of meteorological factors was found to have a significant influence on pollutant transport and deposition in the UK. Using constant emissions and circulation pattern, but the different rainfall fields, the percentage differences in pollutant deposition between extremes (driest 2003 and $2000-$ unusually wet) were almost $20 \%$ of wet deposition and $3-4 \%$ in case of dry deposition. It was also observed that circulation conditions have a greater influence on deposition budget than precipitation. When using years with specific wind conditions (1996 and 2004), $\mathrm{NO}_{\mathrm{y}}$ dry and wet deposition can vary 
(a)
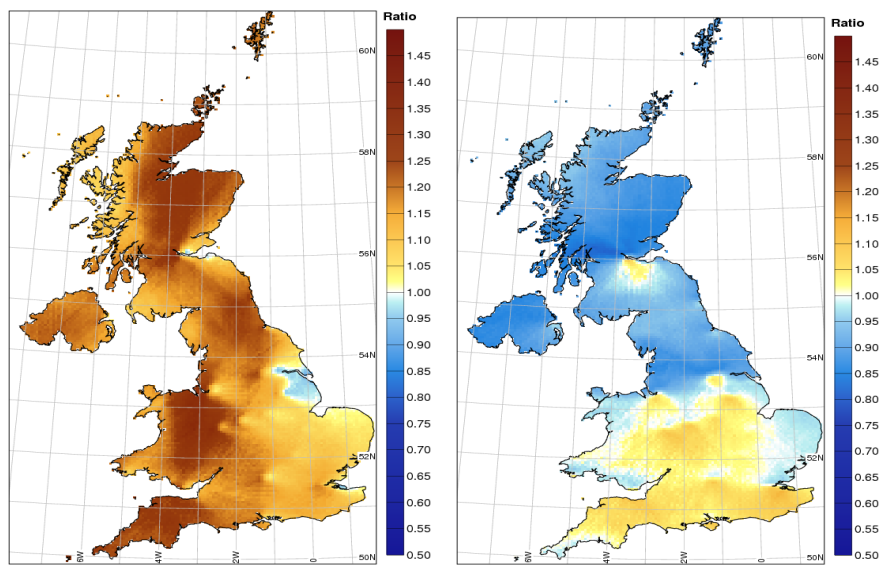

(b)
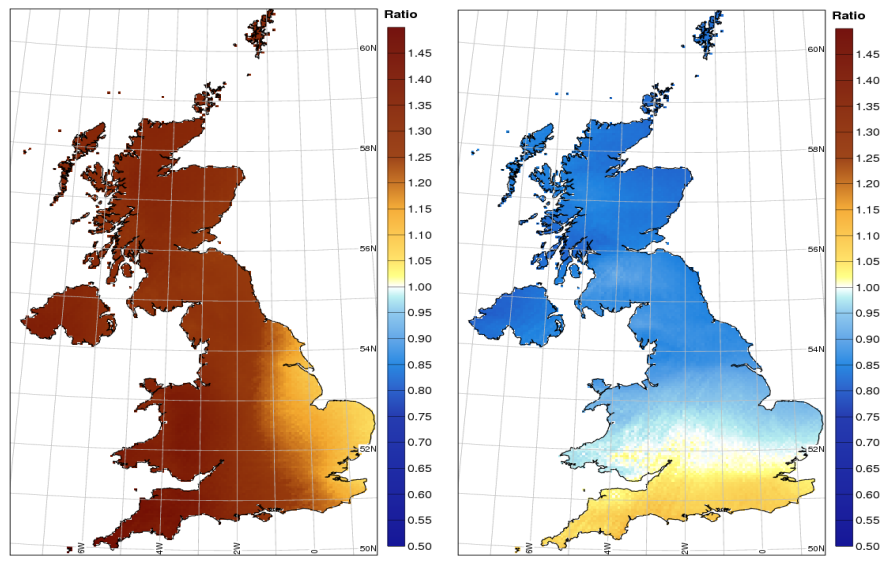

(c)
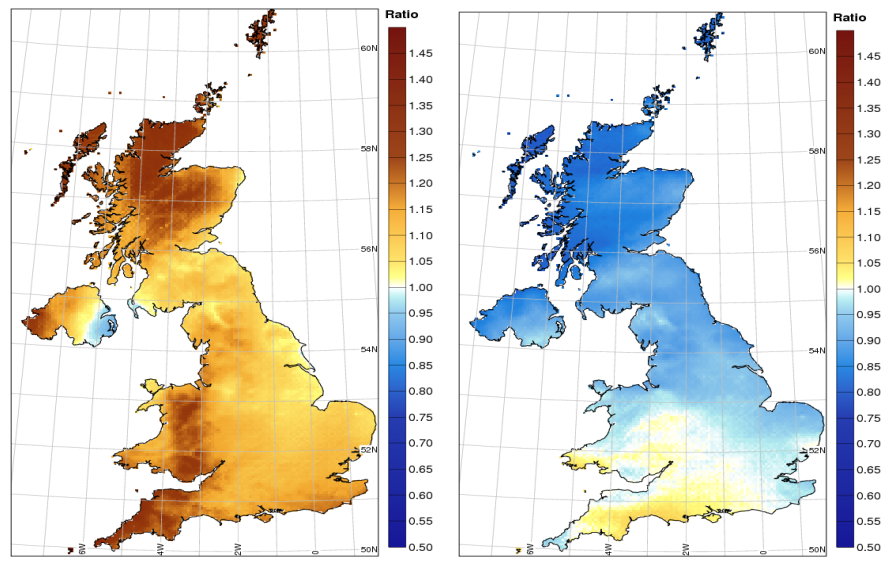

Figure 6: Ratio maps of wet deposition for (a) $\mathrm{SO}_{\mathrm{x}}$, (b) $\mathrm{NO}_{\mathrm{y}}$, (c) $\mathrm{NH}_{\mathrm{x}}$ between FRAME simulation for specific wind data (1996 -left, 2004 - right) and average conditions. 
by more than $10 \%$ and almost $30 \%$, respectively. Such year-to-year variability concerns especially hilly terrain and areas remote from the emission sources. It shows that year-to-year changes in precipitation amount and spatial distribution, together with varying circulation patterns may cover long-term trends in wet and dry deposition due to emission reductions. This is of special importance if the long-term deposition trends are counted in comparison to one selected year, which is considered as a base and then changes are calculated relatively to this year.

\section{References}

[1] ApSimon, H. M., Barker B. M., Kayin S., 1994. Modelling studies of the atmospheric release and transport of ammonia - applications of the TERN model to an EMEP site in eastern England in anticyclonic episodes. Atmospheric Environment, 28, 665-678.

[2] Błaś, M., Dore, A.J., Sobik, M., 1999. Distribution or precipitation and wet deposition around an island mountain in southwest Poland. Quarterly Journal of the Royal Meteorological Society 125, 253-270.

[3] Binkowski, F. S., Shankar, U., 1995. The regional particulate model. Model description and preliminary results. Journal of Geophysical Research 100 (D12). 26191-26209

[4] Choularton, T. W., Gay, M. J., Jones, A., Fowler, D., Cape, J. N., Leith, I. D., 1988. The influence of altitude on wet deposition. Comparison between field measurements at Great Dun Fell and the predictions of the seeder-feeder model. Atmospheric Environment 22, 1363-1371.

[5] Dore, A.J., Choularton, T.W. and Fowler, D., 1992. An improved wet deposition map of the United Kingdom incorporating the seeder-feeder effect over mountainous terrain. Atmospheric Environment 26A, 13751381.

[6] Dore, A.J., Vieno, M., Fournier, N., Weston, K.J. and Sutton, M.A. 2006. Development of a new wind rose for the British Isles using radiosonde data and application to an atmospheric transport model. Q.J.Roy.Met.Soc. 132, 2769-2784.

[7] Dore, A. J., Vieno, M., Tang, Y. S., Dragosits, U., Dosio, A., Weston, K. J., Sutton, M. A., 2007. Modelling the atmospheric transport and deposition of sulphur and nitrogen over the United Kingdom and assessment of the influence of $\mathrm{SO}_{2}$ emission from the international shipping, Atmospheric Environment 41, 2355-2367.

[8] Dragosits, U., Sutton, M.A., Place, C.J., Bayley, A., 1998. Modelling the spatial distribution of ammonia emissions in the United Kingdom. Environmental Pollution 102 (S1), 195-203.

[9] Fournier, N., Dore, A. J., Vieno, M., Weston, K. J., Dragosits, U., Sutton, M. A., 2004. Modelling the deposition of atmospheric oxidized nitrogen and sulphur to the UK using a multi-layer long-range transport model, Atmospheric Environment 38, 683-694. 
[10] Fowler, D., Smith, R., Müller, J., Cape, J.N., Sutton, M., Erisman, J.W., Fagerli, H., 2007. Long-term trends in sulphur and nitrogen deposition in Europe and the cause of non-linearities. Water, Air, \& Soil Pollution, Vol. 7, Numbers 1-3, 41-47.

[11] Hayami, H., Ichikawa, Y., 2001. Sensitivity of long-range transport of sulphur compounds to vertical distribution of sources. Water Air and Soil Pollution130, 283-288.

[12] Hegg, D.A., Hobbs, P.V., 1981. Cloud water chemistry and the production of sulfates in clouds. Atmospheric Environment 15, 1597-1604.

[13] Hulme, M. and Barrow, E. M., 1997. Introducing climate change. pp.1-7 in: Climates of the British Isles: Present, Past and Future M. Hulme and E.M. Barrow, Eds., Routledge, London, pp. 454.

[14] Lagner J., Bergström R., 2001. Impact of climate change on regional air pollution budgets. In: Midgley, P., Reuther, M., Williams, M. (Eds.), Transport and Chemical Transformation in the Troposphere. Springer, Berlin, Heildeberg.

[15] Lagner J., Bergström R., Foltescu V., 2005. Impact of climate change on surface ozone and deposition of sulphur and nitrogen in Europe. Atmospheric Environment 39, 1129-1141.

[16] Lamb, H.H., 1972. British Isles weather types and a register of daily sequence of circulation patterns, 1861-1971. Geophysical Memoir 116, HMSO, London, pp. 85.

[17] Lee, D.S., R.D. Kingdom, Jenkin M., E., Garland J. A., 2000. Modelling the atmospheric oxidised and reduced nitrogen budgets for the UK with a Lagrangian multi-layer long-range transport model. Environmental modelling and assessment 5, 83-104.

[18] Metcalfe, S.E., Whyatt, J.D., Broughton, R., Derwent, R.G., Finnegan, D., Hall, J., Mineter, M., O’Donoghue, M. and Sutton, M.A., 2001. Developing the Hull Acid Rain Model: its validation and implications for policy makers. Journal of Environmental Science and Policy 4, 25-37.

[19] NEGTAP, 2001. Transboundary Air Pollution: Acidification, Eutrophication and Ground Level ozone in the UK. Report of the National Expert Group on Transboundary Air Pollution. DEFRA, London.

[20] O’Neill P., 1998, Chemia środowiska, PWN, Warszawa.

[21] Radojevic, M., Tyler, B.J., Hall, S., Penderghest, N., 1995. Air oxidation of S(IV) in cloud-water samples. Water, Air and Soil Pollution 85, 1985 1990.

[22] Singles, R.J., M.A. Sutton \& K.J. Weston, 1998. A multi-layer model to describe the atmospheric transport and deposition of ammonia in Great Britain. Atmospheric Environment 32, 393-399.

[23] Vieno, M., 2005. The use of an Atmospheric Chemistry-Transport Model FRAME over the UK and the development of its numerical and physical schemes. PhD thesis, University of Edinburgh. 